\title{
El control constitucional de las barreras burocráticas y las facultades del INDECOPI
}

\author{
Aníbal Quiroga León ${ }^{1}$
}

\section{Introducción}

Las leyes que regulan y protegen en la normatividad jurídica vigente en el Perú la "libertad de mercado" y las reglas de la "libre competencia" recusan drásticamente la imposición de "barreras burocráticas" irracionales o ilegales. Ello aparece claramente sancionado en el actual texto del Art. 26 BIS del Decreto Ley No 25868, "Ley de Organización y Funciones del Instituto Nacional de Defensa de la Competencia y de la Protección a la Propiedad Intelectual" (Ley del INDECOPI), y los problemas referidos a los alcances normativos e interpretativos que este numeral trae en conjunto con el Art. 50 del D. Leg. No 807 (D. Leg. ampliatorio de facultades), que le fue adicionado el 18 de abril de 1996.

La norma legal bajo análisis señala a la letra que:

"Art. 26 BIS.- La Comisión de Acceso al Mercado es competente para conocer los actos y disposiciones de las entidades de la Administración Pública, incluso en el ámbito municipal o regional, que impongan barreras burocráticas que impidan u obstaculicen ilegal o irracionalmente el acceso o permanencia de los agen-

1 Profesor Principal de la Facultad de Derecho de la PUCP del Perú. Ex-Vocal Suplente de la Corte Superior de Justicia de Lima. Ex-Profesor de la Maestría en Derecho Empresarial de la Escuela de Post-Grado de la Universidad de Lima. Abogado en ejercicio. 
tes económicos en el mercado, en especial de las pequeñas empresas, y de velar por el cumplimiento de las disposiciones del Decreto Legislativo No 776 y la Ley No 25035, en especial los principios generales de simplificación administrativa contenidos en su artículo $2^{\circ}$, así como las normas reglamentarias pertinentes. Ninguna otra entidad de la Administración Pública podrá arrogarse estas facultades. La Comisión, mediante resolución, podrá eliminar las barreras burocráticas a que se refiere este artículo.

La Comisión podrá imponer sanciones y multas al funcionario o funcionarios que impongan la barrera burocrática declarada ilegal, sin perjuicio de la responsabilidad administrativa y la formulación de la denuncia penal correspondiente, de ser el caso. La escala de sanciones es la siguiente: falta leve con sanción de amonestación; falta grave con multa de hasta dos (2) UIT y falta muy grave con multa de hasta cinco (5) UIT.

En caso que presunta barrera burocrática haya sido establecida en un Decreto Supremo o Resolución Ministerial, la Comisión no podrá ordenar su derogatoria o inaplicación ni imponer sanciones. En tal supuesto el pronunciamiento de la Comisión se realizará a través de un informe que será elevado a la Presidencia del Consejo de Ministros para ser puesto en conocimiento del Consejo de Ministros a fin de que éste adopte las medidas que correspondan.

Lo dispuesto en el párrafo que antecede también será de aplicación a la Comisión de Reglamentos Técnicos y Comerciales a que se refiere el artículo anterior." (las letras en negritas son nuestras).

Ello, en la estructura del INDECOPI, es labor fundamental de la Comisión de Acceso al Mercado (CAM) en una primera instancia, y del Tribunal de Defensa de la Competencia y de la Propiedad Intelectual (TDCPI) en una segunda y definitiva instancia administrativa. De allí, lo será del Poder Judicial solo si el administrado afectado desea recurrir a la acción de control constitucional del Poder Judicial sobre los actos particulares de la administración pública denominada Acción Contenciosa Administrativa, y que se halla contenida en el Art. $148^{\circ}$ de la Constitución Política del Estado.

Vamos a desarrollar en las siguientes líneas ocho criterios procurando establecer cierta sistematicidad lógica en su formulación, de manera 
que el lector pueda seguir el desarrollo de este trabajo en un orden que permita hacer más claro lo que se pretende apuntar, a título de esbozo de contribución a una discusión mayor, ciertamente más rica y amplia, y que necesariamente escapa a los límites del presente enunciado.

\section{Análisis}

Primero: ¿Cuál es la naturaleza jurídica de los actos de la Administración Pública en materia administrativa, en materia legislativa y en materia jurisdiccional?

La Administración Pública es una de las actividades del Estado de Derecho basado en una Constitución en la que los diversos órdenes competenciales son determinados con mayor o menor claridad, distribuyendo el ejercicio legítimo del Poder Político. En eso es célebre la definición de Kaegi ${ }^{2}$, quien ha señalado que "La Constitución jurídica transforma el desnudo poder político en legítimo poder jurídico".

En el mundo contemporáneo no queda duda que el Ejecutivo es el órgano del Estado que tiene la mayor responsabilidad en la Administración Pública. El Legislativo tiene la mayor responsabilidad en la actividad legislativa y en el control de los actos del Estado. Y el Poder Judicial tiene la mayor responsabilidad en la actividad jurisdiccional del mismo Estado.

A lo anterior se le debe agregar la realidad y funcionamiento de diversos órganos constitucionales autónomos e independientes que, perteneciendo igualmente al Estado, no se insertan en ninguna de sus tres principales manifestaciones (Ejecutiva, Legislativa y Judicial), pero que pueden ser más o menos cercanas o afines a unas u otras. Para ello, baste citar, por ejemplo, el Banco Central de Reserva, la Defensoría del Pueblo, el Ministerio Público, el Tribunal Constitucional, el Consejo Nacional de la Magistratura, el Jurado Nacional de Elecciones, etc.; y que han de realizar-como todas las manifestaciones del Estado-, sea lo principal o no, igualmente tareas legislativas, administrativas y jurisdiccionales en sus respectivos ámbitos de competencia y dentro de sus respectivas limitaciones constitucionales.

2 Kaegi; cit. por Carla Pegorari Rodríguez. La Interpretación Constitucional; Tesis, Fac. Der. Puc; Mimeo, Lima, 1988. 
Lo anterior reposa en una bien conocida Teoría de Separación de los Poderes que la unánime doctrina del Derecho Constitucional ha atribuido a Carlos María de Secondat, Barón de Montesquieau ${ }^{3}$, y a quien siguiera J.J. Rousseau, y que ahora se halla reformulada por la pacífica teoría del control inter-órganos e intra-órganos de Karl Loewenstein 4 , bajo la idea aristoteliana de que "sólo el poder controla al poder", por lo que el poder absoluto previo a la conformación de Estado de Derecho se diluía con su división absoluta y el establecimiento de mecanismos de controles de sus partes entre sí ("pesos y contrapesos"; "checks and balances", etc.).

En consecuencia, al margen de la tarea primordial que tenga designado realizar por la Constitución un determinado órgano del Estado, es obvio que también realiza las otras dos atribuciones de modo claro. Nos explicamos: si bien, por ejemplo, el Poder Judicial juzga, también habrá de administrar su propia realidad generando actos administrativos de orden particular, y también habrá de legislar mediante actos administrativos de carácter general. En el primer caso, estos actos administrativos particulares no pueden superar su ámbito de competencia, y deben realizarse en el marco de la normatividad genérica de la administración pública ( $\mathrm{y}$ no mediante las leyes que le permiten juzgar los casos jurisdiccionales), y los actos legislativos no podrán tener rango normativo ni formal de ley de la República, pero representan un contenido material de ley y se insertarán dentro del ordenamiento jurídico con su respectiva jerarquía por debajo de las leyes y sujetas al control legislativo que la Constitución establece. Del mismo modo, es indudable que el Congreso Nacional tiene por principal atribución la generación, control e interpretación legislativa, pero no es menos cierto que dentro de su ámbito de competencia también genera actos administrativos de carácter particular (por ejemplo una licencia, la administración de su presupuesto, de su personal, determinación de sanciones y responsabilidades, etc., de modo acorde con la normatividad

3 Barón de Montesquieau. Esprit des Lois; 1, Cap. VI. "Il n'y a point de liberté si la puissance de juger n'est pas sépareé de la puissance législative et de l'executive"; cit. por Aníbal Quiroga León: "Las Garantías Constitucionales de la Administración de Justicia”, en: La Constitución Diez Años Después; Inst. Const. \& Soc., y Fund. Naumann, Lima, 1989.

4 Karl Loewenstein. Teoría de la Constitución; 2da. Ed., Barcelona, 1970; cit. por Eduardo García de Enterría. La Constitución como Norma y el Tribunal Constitucional; Ed. CIVITAS, 3era. Ed., Madrid, 1985 
genérica del Estado), sino que también contendrá una tarea jurisdiccional en los procesos administrativos que lleve a cabo o en los procesos de control político que la carta constitucional le faculta expresamente (por ejemplo, el antejuicio político que regula los Arts. $99^{\circ}$ y $100^{\circ} \mathrm{de}$ la Constitución Política del Estado).

Por ello mismo, resulta incuestionable que la administración pública tiene por finalidad esencial ejecutar actos y hechos de la administración, mediante los actos jurídico-administrativos de efectos particulares, o mediante los hechos administrativos discrecionales con trascendencia jurídica (decisiones de la autoridad administrativa); y al mismo tiempo tiene una labor legislativa "derivada" al poder expedir actos administrativos de alcance general (reglamentos) con contenido material de ley e insertos en el ordenamiento jurídico, dentro del rango legislativo que le corresponda en la pirámide jurídica kelseniana. Asimismo, tiene una facultad jurisdiccional administrativa en los procesos administrativos que lleva de acuerdo con sus diversos órdenes competenciales, pudiendo hablarse de una "justicia (o jurisdicción) administrativa", sólo que ésta siempre estará bajo el control del Poder Judicial mediante la Acción Contencioso Administrativa que prevé el Art. $148^{\circ}$ de la Carta Constitucional de 1993, salvo en las muy contadas excepciones referidas a los "casos políticos no judiciales".

Por jurisdicción puede hablarse, desde la Teoría General del Proceso ${ }^{5}$, en una doble acepción: en sentido lato $0^{6}$ en sentido estricto ${ }^{7}$ La gran diferencia radica, en puridad, en que la jurisdicción que no es la del Poder Judicial (la administrativa, la privada, la arbitral, la asociativa, la política, etc., con excepción de la jurisdicción militar por expresa previsión constitucional, Art. 139\%, Inc. lero., 2do. parágrafo) normalmente se encuentra sujeta al posterior control judicial (con las ya ano-

5 Aníbal Quiroga León. "Conceptos Básicos en el Estudio del Derecho Procesal: a propósito de la Ciencia del Proceso"; Rev. Derecho No. 40, Fac. Der. PUC, Lima, 1986.

6 Su definición sería: "Por jurisdicción (iuris-dictio=decir derecho) puede entenderse toda declaración de derecho que se hace en nombre del Estado en una caso concreto para la determinación de un conflicto o de incertidumbre de derecho entre sí y los particulares, o entre los particulares entre sí."

7 Su definición sería: "Por jurisdicción (iuris-dictio=decir derecho) debe entenderse la posibilidad del Poder Judicial, en nombre del Estado, de decir el derecho que corresponda en un caso concreto en la determinación de un conflicto o de incertidumbre de derecho entre los particulares, o entre los particulares y el Estado por medio dela Administración Pública." 
tadas excepciones de los llamados casos "no judiciables" básicamente referidos a excepcionales decisiones políticas o de política exterior que no pueden, por su naturaleza, ser materia de controversia ante un Estrado Judicial); en tanto que la jurisdicción del Poder Judicial no es recontrovertible por ser terminal y, por ende, es la única que genera el efecto y la cualidad de la Cosa Juzgada (res iudicata), también por expreso mandato constitucional ${ }^{8}$.

En consecuencia, nada obsta para que la Administración Pública realice una tarea verdaderamente jurisdiccional en el orden administrativo; esto es, conozca de una controversia concreta entre su realidad administrativa y los particulares, o entre particulares arbitrando una controversia entre éstos, interprete y aplique el derecho pertinente a dicho caso concreto tal como lo haría cualquier juez (no hay diferencia sustancial entre una y otra actividad), con las mismas facultades, alcances interpretativos y de aplicación de la ley sustantiva y procesal ${ }^{9}$.

Segundo: Concepto de Administración Pública como sujeto activo de la conducta que genera la "barrera burocrática".

El concepto de administración pública, como se ha señalado en las líneas precedentes, está referido a las atribuciones que la Constitución confiere a los diferentes órganos que la conforman, sin distinguir en ello el nivel que tengan dentro de la jerarquía o niveles de órganos de la administración pública, o del órgano del Estado de la que provengan las diversas actividades administrativas.

Una de las manifestaciones de la función de la administración pública se da a través de los actos administrativos; esto es, los actos jurídicos de la administración pública (a diferencia de los denominados "hechos de la administración"), las declaraciones de voluntad unilaterales tomadas por cualquiera de los órganos y organismos que confor-

8 La cualidad que la doctrina de la Teoria General del Proceso le reconoce a la cosa juzgada (res iudicata) se define en tres aspectos: su inimpugnabilidad, su inmutabilidad y su coercibilidad; atributos de los que no goza, normalmente, una decisión de la justicia administrativa. Ver Aníbal Quiroga León. Las Garantías Constitucionales (...); Op. cit.

9 En realidad la única tarea que no le está facultado a aquel Juez que no sea del Poder Judicial (administrativo, privado, político, etc.) es la de realizar la función del control judicial de las leyes, que prevé la concordancia de los Arts. 138 ${ }^{\circ}$, 2da. Parte, de la Constitución, y el Arr. $14^{\circ}$ del TUO de la Ley Orgánica del Poder Judicial, potestad restringida de modo exclusivo y excluyente para los Jueces del Poder Judicial. 
man la administración pública, y que suponen que ésta sea el sujeto activo de lo que determine por el sólo hecho de ser el ente que se encarga de manifestar la voluntad del Estado respecto a situaciones diversas, ya sean de carácter general o de carácter particular.

La administración pública es siempre el sujeto activo de los actos administrativos, pues será ella la que otorgue y traslade hacia los ciudadanos, y hacia los demás órganos del Estado, la manifestación de voluntad del Estado válidamente determinada por el orden competencial que la sustente; manifestación que produce efectos subjetivos puesto que tiene consecuencias en los sujetos (incluyendo en ello los otros órganos del Estado que para este efecto son también "sujetos"), no importando que estemos ante un acto administrativo de carácter general o de carácter particular.

La emisión de un acto administrativo supone muy claramente que los órganos de la administración pública, en ejercicio de las facultades que les confiere la Constitución y el TUO de la Ley General de Procedimientos Administrativos, están ejerciendo la jurisdicción administrativa, entendida ésta dentro de los alcances de lo expuesto líneas arriba.

La jurisdicción administrativa es entonces la facultad de todo órgano que es parte de la administración pública de "decir derecho" a un caso concreto de orden administrativo con efectos intersubjetivos (interpartes), lo que requiere que el órgano emisor del acto administrativo, luego de apreciar el hecho que será materia de la declaración que se expida, sea interpretado dentro de los alcances de las normas legales vigentes y se sancione como legal o no. No es ajena a la jurisdicción administrativa la interpretación de las normas que deberá aplicar, bajo cualesquiera de los métodos que la hermenéutica jurídica reconoce ${ }^{10}$, aplicar analogías, cubrir deficiencias o defectos en la ley frente a la resolución de casos concretos e, inclusive, hacer interpretaciones integradoras frente a los vacíos y lagunas normativas, respetando sin duda los principios generales del derecho y los presupuestos y presunciones jurídicas que el ordenamiento jurídico reconoce, admite y aplica diariamente. No obstante lo anterior, debemos dejar plenamente esta-

10 Francesco Messineo. Conocimiento, Interpretación e Integración de las normas jurídicas de derecho; Mimeo, Sep. Fac. Der. PUC del Perú; Lima, 1977; cit. por Carla Pegorari Rodríguez. La Interpretación Constitucional; Op. cit. 
blecido que la facultad de inaplicación de las normas legales por colisión constitucional ("judicial review" o "control judicial de la constitucionalidad de las leyes") se encuentra exclusivamente reservada de modo restrictivo a los jueces del Poder Judicial y sólo en el ejercicio de la función jurisdiccional -entendida en su sentido estricto- y denominado por la doctrina constitucional como el Control Difuso de la Constitucionalidad de las normas, y que se halla contenido en el Art. $138^{\circ}, 2$ da. parte, de nuestra Carta Constitucional.

Es la administración pública el sujeto activo de todas las declaraciones de voluntad que realiza y de la propia voluntad del Estado, y serán sujetos pasivos de la misma los ciudadanos ya sea de modo particular o de modo general, dependiendo la naturaleza del acto administrativo que se esté dictando, u otras entidades de la administración pública cuando estén: (a) en calidad de sujetos pasivos; y, (b) cuando ello se encuentra dentro del ámbito competencial del sujeto activo.

Por lo tanto, cuando el Art. 26 BIS de la Ley de INDECOPI se refiere a las "barreras burocráticas" que impidan u obstaculicen (ilegal o irracionalmente) el acceso o permanencia de los agentes económicos en el mercado, en especial de las pequeñas empresas, estas "barreras burocráticas" podrán estar contenidas, sin duda alguna, en los actos administrativos particulares o genéricos de la administración pública, o en los hechos de la administración, incluyendo en ello a las entidades o facultades administrativas municipales o regionales, que hace de esta administración pública, municipal o regional, verdaderos sujetos pasivos de esta norma legal y, por lo tanto, sujetos del control legal y legítimo de la CAM en lo que es materia de su competencia en la Ley de INDECOPI. Dicho de otro modo, no hay entidad de la actividad pública del Estado, incluyendo por cierto a la actividad municipal o regional que sin duda alguna pertenece igualmente al Estado, que se halle exenta del control de la CAM siempre y cuando esta actividad presente en sus actos administrativos, genéricos o particulares, incluyendo a los hechos de la administración, "barreras burocráticas" que son definidas por la propia Ley de INDECOPI como aquellas disposiciones de orden ilegal o irracional que tienen por consecuencia o finalidad (cualesquiera de ambas) impedir u obstaculizar el acceso o permanencia de los agentes económicos en el mercado, otorgándole preferencial atención por parte de la CAM a la pequeña empresa, por expreso imperio legal. 
Tercero: ¿De quién sería la responsabilidad en el dictado de un Acto Administrativo que implique una barrera burocrática?

Un acto administrativo expresado por la autoridad administrativa o un hecho de la administración-, tiene como sujeto activo como ya hemos señalado a la autoridad administrativa que lo emita, expida o ejecute; por ejemplo ¿qué sucede en el caso de una resolución administrativa de carácter particular emitida por la Dirección de Rentas de cualquier gobierno local que implique la transgresión de cualesquiera norma de nuestro ordenamiento legal negando o impidiendo el derecho de un ciudadano reclamante o sancionándole con la privación o restricción de un derecho?. El particular que de ese modo se vea afectado por tal resolución, luego de agotar la vía administrativa previa e interna como presupuesto de procesabilidad ineludible conforme lo reconoce la pacífica y unánime doctrina del Derecho administrativo, podrá acudir -sólo si lo desea- al Poder Judicial a fin de impugnar la mencionada resolución por medio de la acción de control judicial sobre los actos administrativos de efectos subjetivos particulares (a ello se refiere la Constitución cuando expresa causar estado) por medio de la Acción Contencioso Administrativa, conforme a la previsión del Art. $148^{\circ}$ de la Constitución Política del Estado, obteniendo por medio de su petitorio la misma prestación que administrativamente le ha sido negada, sólo que esta vez a través de una sentencia judicial ${ }^{11}$, y, por lo mismo, en uso del derecho de defensa y de la legitimación pasiva obligatoria (litis-consorte necesario) se deberá emplazar al órgano emisor de la resolución, es decir a la Dirección General de Rentas del Gobierno Local, y ésta luego de notificada será quien ponga en conocimiento de ello al Departamento Legal de la Municipalidad para que se pueda defender conforme a lo dispuesto en la ley.

Si aplicamos lo señalado en el punto anterior a los casos materia de la consulta, llegaremos a la conclusión de que el emplazado por la CAM del INDECOPI, en un supuesto de emisión de un acto administrativo que constituya una barrera burocrática, deberá necesariamente ser el órgano emisor del acto administrativo como sujeto pasivo (litis-consor-

11 De allí que la Acción Contencioso Administrativa se defina en la doctrina del Derecho Procesal Constitucional como una acción de control del Poder Judicial sobre la actividad administrativa de la Administración Pública, en actos y hechos administrativos de efectos intersubjetivos. 
te necesario) que habiendo sido emplazado por generar la barrera burocrática, debe ser materia de control por parte de la CAM dentro de los alcances de su competencia expresamente prevista en el texto de la ley; sea este un órgano dependiente o no de otro de mayor jerarquía, centralizado o descentralizado.

La CAM, en todo caso, dentro de los límites de su competencia administrativa legislativamente desarrollada, será sujeto de derecho público con interés en aquellos procesos administrativos en los cuales se esté resolviendo causas en las que se estén viendo materias relativas a las de la comisión, y podrá apersonarse a las mismas a fin de intervenir como el órgano encargado del control de la no imposición de "barreras burocráticas" que afecten el desarrollo del libre mercado; pudiendo participar como un tercero legitimado coadyuvante del particular que se pudiere ver afectado o beneficiado por la imposición de las "barreras burocráticas".

Como ya señaláramos en puntos anteriores, los actos administrativos pueden ser de dos tipos: (a) aquellos que tienen efectos particulares y sobre los cuales nos hemos referido en el punto anterior; y, (b) aquellos que tienen efectos generales, de efectos normativos, generales, tales como decretos supremos reglamentarios, resoluciones supremas de efectos generales, resoluciones ministeriales, resoluciones directorales, subdirectorales, etc., es decir, todos aquellos actos administrativos destinados a generar una normatividad genérica y que no contengan un acto administrativo de efectos intersubjetivos, es decir, que sean leyes en sentido material, aunque no lo sean en sentido formal, según la muy conocida diferenciación de $\operatorname{Karl}$ Loewenstein ${ }^{12}$; esto es, verdaderas normas legales en sentido material y que por ello son denominadas por la doctrina como de legislación derivada o leyes ejecutivas emanadas de la administración pública.

La doctrina constitucional y la legislación constitucional peruana facultan también al Poder Judicial a ejercer el control de la legalidad y constitucionalidad de las normas reglamentarias y, en general, de legislación derivada de la administración pública (cualquiera sea el órgano u origen de su emisión), mediante la Acción Popular, acción judicial de control de los actos normativos del Poder Ejecutivo (y de la adminis-

12 Karl Loewenstein. Op. cit. 
tración pública, o de las manifestaciones administrativas en general de cualquiera de los órganos del Estado); y que se encuentra contenida dentro del Art. 200, Inc. 5to., de la Constitución Política de 1993 no obstante no ser técnicamente una Garantía Constitucional como impropiamente allí se le denomina, sino una verdadera acción de Control Constitucional ${ }^{13}$. Así tenemos que el mencionado artículo constitucional señala, en su parte pertinente, lo siguiente:

\section{"Art. $200^{\circ}$.- Son garantías constitucionales:}

(...)

5. La Acción Popular, que procede, por infracción de la Constitución y de la ley, contra los reglamentos, normas administrativas y resoluciones y decretos de carácter general, cualquiera sea la autoridad de la que emanen.

(...)"

Es la Acción Popular, conforme a lo dispuesto en la Ley Procesal de Acción Popular (Ley No 24968); aquella acción de control por la cual cualesquiera persona puede recurrir ante un Tribunal de Justicia (de allí la denominación de Acción Popular, que es de orden procesal y subraya una "legitimación abierta" en el órgano jurisdiccional) y solicitarle como pretensión la derogación total o parcial de una norma de legislación derivada de la administración pública por contravenir a lo dispuesto en la Constitución, o en una norma de mayor jerarquía, o en el caso de normas de la misma jerarquía una de naturaleza especial por razón de la materia o del tiempo. La característica esencial de este proceso constitucional es la de ser de legitimación abierta, esto es que no se requiere un interés particular, probado y actual, para obrar como en el caso de la Acción Contencioso Administrativa (que sólo está reservada para el afectado y de quien de él derive legítimamente sus derechos particulares afectados), y está destinada a que cualesquier persona pueda hacer uso del control constitucional sobre la legislación derivada de la admi-

13 Para poder comprender esto con mayor facilidad, se puede seguir la siguiente inferencia lógica: La Acción de Inconstitucionalidad de las Leyes es a la Ley en el Tribunal Constitucional, lo que la Acción Popular es a la legislación derivada de la administración pública en el Poder Judicial. Cambia el objeto y el escenario, por la razón jurídico constitucional y la naturaleza jurídica -y por ende los efectos- son los mismos. 
nistración pública, con la finalidad de que se respete la prevalencia de la Constitución y de las normas legales de jerarquía superior o especial, respecto de la cuestionada.

En el marco de lo antes expuesto la CAM, por intermedio del INDECOPI, podría ver necesario acudir al órgano jurisdiccional correspondiente, en este caso la Corte Superior de Justicia del lugar de donde ha sido dictada la norma cuestionada, a fin de promover mediante la Acción Popular -que es de orden abstracto- la derogación de una norma administrativa de efectos generales y, dentro de su alcance de competencia legalmente establecido, encuentre que regula una barrera burocrática, y deberá ser el Poder Judicial (la Sala Constitucional y Social de la Corte Suprema de Justicia de la República en segunda y definitiva instancia) la que determine finalmente y con calidad de cosa juzgada vinculante, si se está violando la Constitución o la legislación en materia de libre competencia y de acceso al mercado que se acusen como vulneradas.

Esta facultad de control legislativo de orden constitucional está únicamente otorgada al Poder Judicial, y en este caso se convierte en un órgano de control constitucional que tiene como función hacer prevalecer ante todo el cumplimiento de la Constitución y las leyes, así como la jerarquía normativa. Se trata, en definitiva, de que el Poder Judicial haga uso de sus facultades de órgano de control constitucional, entablando un equilibrio en las relaciones inter-órganos a partir de una interpretación constitucional autorizada y con calidad de cosa juzgada constitucional (interpretación constitucional auténtica) ${ }^{14}$.

Cuarto: Concepto e interpretación de lo que puede constituir una barrera burocrática ilegal o irracional.

El concepto de barrera burocrática se encuentra estrechamente ligado al de los de economía de mercado, libertad de mercado y libre competencia; marco conceptual en el que puede ser definida como aquellos medios que son generados por la administración pública y que transgreden los principios básicos de libre competencia en el mercado.

Los Arts. $58^{\circ}$ y $61^{\circ}$ de la Constitución Política del Estado señalan:

14 Aníbal Quiroga León. “El Modelo de la Constitución de 1979”; en: La Constitución Diez Años Después; Op. cit.; pp. 38 y ss. 
"Art. 58 . - La iniciativa privada es libre. Se ejerce en una economía social del mercado. Bajo este régimen, el Estado orienta el desarrollo del país, y actúa primordialmente en las áreas de promoción de empleo, salud, educación, seguridad, servicios públicos e infraestructura.

(...)

Art. 61․- El Estado facilita y vigila la libre competencia. Combate toda práctica que la limite y el abuso de posiciones dominantes o monopólicas. Ninguna ley o concertación puede autorizar ni establecer monopolios.

(...)"

El régimen económico de nuestra carta constitucional es uno que se instala dentro del marco de la libertad económica, tomando como punto de partida la vigencia de la denominada economía social de mercado, concepto que no puede considerarse ajeno a la Constitución de 1993, en actual vigencia, por más liberal que sean las determinaciones constitucionales frente a la Constitución de 1979(D). Es por esta razón que se han venido dictando una serie de dispositivos legales que tienen como finalidad la reforma de las instituciones y de los diversos marcos de desarrollo económico, como la Ley Marco de Crecimiento de la Actividad Económica, o como el Decreto Ley No 25868 mediante el cuál se crea precisamente al INDECOPI.

Lo que se ha buscado a través de estas reformas legislativas, y con la creación misma del INDECOPI, es que la nueva política económica procure el desarrollo y afianzamiento de la libre competencia como marcos esenciales del desarrollo de un mercado "sano", sin proteccionismos distorsionantes o sin "barreras burocráticas", es decir, sin la intervención innecesaria de la administración pública (o, en todo caso, con sólo la necesaria y limitada intervención en tanto no constituya una "barrera burocrática" ilegal o irracional. Entonces, sí pueden haber "barreras burocráticas" en tanto sean legales y razonables, necesarias por excepción), generando iguales distorsiones por un burocratismo mayor, o por una innecesaria intervención estatal en asuntos que deben ser librados a las fuerzas del mercado mismo, y a su autocontrol etc., de modo tal que generen sobrecostos para unos, se desalienten actividades económicas para otros, o se beneficien indebidamente a unos u otros por su posicionamiento en el mercado, o por su envergadura (capaci- 
dad económica de resistencia o de asimilación de sobrecostos) frente a los más débiles.

Por ello la previsión legal de que la actividad del INDECOPI, a través de la CAM tenga especial atención o focalización interpretativa en el caso de las pequeñas empresas (y por extensión interpretativa, de las medianas empresas frente a las grandes), ya que se desea por parte de la Constitución y del Estado la participación "natural" de todos los agentes económicos en el mercado como fortalecimiento de la estructura económica de la Nación, fuente de recursos y de ingresos para el Estado mismo, fuente de trabajo (aspecto social) y, en suma, el fortalecimiento del país a partir de una sólida economía que nos permita participar, al mismo tiempo, de la manera más libre y segura en el mercado internacional. Estos deben ser, desde el punto de vista constitucional y legislativo, los marcos del crecimiento de la empresa y la realización efectiva de las normas programáticas que en materia económica contiene nuestra Carta Constitucional de 1993, adecuadamente interpretadas por los agentes de la Administración Pública y del Poder Judicial, dentro de sus respectivos marcos de competencia y jurisdicción.

Es bajo el régimen actual y conforme a los imperativos mandatos constitucionales antes señalados, que se determina como una de las funciones de la CAM impedir que existan "barreras burocráticas", que contravengan la existencia y desarrollo en nuestra economía en la denominada "libre competencia".

En el caso de las "barreras burocráticas" la CAM deberá tener presente que, como parte integrante de la administración pública (Poder Ejecutivo), carece de competencia constitucional para determinar por sí misma la inaplicación de las normas particulares o generales que sean dictadas por otro órgano u organismo de la misma administración pública, puesto que en calidad de órgano que ejerce jurisdicción administrativa carece de tal facultad que sólo está reservada, como ya se ha dicho, a los jueces del Poder Judicial. Es evidente que la actual redacción del Art. $26^{\circ}$ BIS de la Ley del INDECOPI no faculta -y no podría hacerlo constitucionalmente- a ejercitar un "control normativo de legalidad y/o de constitucionalidad de los actos y hechos de la administración pública" en los que encuentre disposiciones específicas o genéricas -incluyendo en ello a la administración municipal o a la administración regional- "que impongan barreras burocráticas que impidan u 
obstaculicen ilegal o irracionalmente el acceso o permanencia de los agentes económicos en el mercado, en especial de las pequeñas empresas" (SIC); pero sí puede establecer válidamente la condición de ilegalidad o irrazonabilidad en dichas norma, actos o hechos y disponer las sanciones del caso, en cada caso concreto; pues lo contrario implicaría irrogarse una facultad de control normativo o de legalidad de la Constitución o de las leyes que la propia Constitución no permite a ningún órgano de la propia administración pública.

Para ello, necesariamente debe hacerse un previo análisis interpretativo y legislativo de las mismas -y sí se halla facultada a hacer interpretación legal (hermenéutica), a través de todos los métodos de interpretación jurídica que el derecho reconoce como ya se ha señalado- $y$, en consecuencia, al hacerlo así estará legal y constitucionalmente facultada a establecer las sanciones y correcciones a los actos concretos en que ello halla acontecido (la existencia de una "barrera burocrática"), determinando su sanción, eliminación o levantamiento, al mismo tiempo que los criterios (en uso de la jurisdicción administrativa que le confiere) para evitar que ello vuelva a acontecer en el mismo o en similares casos, a través de una jurisprudencia administrativa de carácter vinculante para la propia administración pública, y de orden supletorio para el Poder Judicial. Por ello mismo, no le está asignada ni permitida a la CAM, como ya queda dicho, la potestad de ejercer el control normativo sobre la administración pública, la municipal ni la regional, posibilidad de inaplicar, pues ello -como ya se ha explicado- queda reservado de modo exclusivo y excluyente al Poder Judicial, único órgano del Estado con capacidad de derogar una norma de legislación derivada de carácter general, único también con capacidad de declarar la inaplicación de una ley a un caso judicial concreto -judicial review o "control difuso" de la constitucionalidad de las leyes- (Arts. 138, $2 \mathrm{da}$. parte de la Constitución y $14^{\circ}$ del TUO de la Ley Orgánica del Poder Judicial), y único para la determinación de la impugnación de un Acto Administrativo con efecto particular por medio de la Acción Contencioso Administrativa.

Lo primero mediante una sentencia con efectos generales (Erga Omnes) en un proceso judicial de orden constitucional de Acción Popular, lo segundo dentro de los límites de la institución del Control Judicial de la Constitucionalidad de las Leyes en el procedimiento estatuido en el Art. $14^{\circ}$ del TUO de la Ley Orgánica del Poder Judicial 
y dentro de una sentencia judicial de fondo en un caso concreto de colisión de leyes con las normas de la Constitución, según la determinación judicial; y lo tercero en el caso de una sentencia judicial en una Acción Contencioso Administrativa frente a una reclamación particular de un acto administrativo, o hecho de la administración, de efectos particulares, y sólo a petición del ciudadano que ha sido desatendido por la administración pública, legitimado para el efecto ${ }^{15}$. Todos esos son instrumentos del Derecho Procesal Constitucional ${ }^{16}$.

Quinto: ¿Puede la CAM declarar que existe una "barrera burocrática"?

La CAM tiene como una de sus funciones legales el velar porque todos los órganos de la administración pública, sin excepción, incluyendo a los municipales o regionales, dentro de la prestación o regulación de bienes y servicios que estén relacionados con el acceso o permanencia de los diversos agentes económicos, no impongan "barreras burocráticas" que impidan u obstaculicen ilegal o irracionalmente tal acceso o permanencia, dando preferente atención a los agentes económicos constituidos por pequeñas empresas.

Ello significa que el concepto "barrera burocrática" está definido legalmente como "actos y disposiciones de la administración pública, incluyendo a la actividad administrativa municipal y la regional, que impidan u obstaculicen ilegal o irracionalmente el acceso o permanencia de los agentes económicos en el mercado". De allí se puede inferir, con claridad, que por "barrera burocrática" se define legalmente a los actos y disposiciones administrativas del Estado, cualesquiera sea su ámbito de competencia, que tengan por objeto o finalidad -o inclusive finalidad no deseada o no querida- que constituya impedimento u obstáculo contra la legislación de la libre competencia, o su aplicación fuera de los márgenes del principio de razonabilidad (entendiendo la

15 Por eso se define a la Acción Contencioso Administrativa como una acción de control residual de orden subjetivo, sólo reservada al ciudadano que emplaza a la Administración Pública ante su contralor, el Poder Judicial, a fin de obtener de la sentencia judicial la prestación que la Administración Pública ha negado en acto de y dentro de su facultad discrecional en la jurisdicción administrativa. El supuesto inverso no existe en el Derecho Procesal Constitucional.

16 Aníbal Quiroga León. Una aproximación a la Justicia Constitucional: El Modelo Peruano; AAVV, (Aníbal Quiroga León-Compilador); Fac. De. PUC, Lima, 1990; pp. 147 y ss. 
expresión "irrazonablemente" por lo antes señalado) y que determinen el acceso o permanencia de los agentes económicos en el mercado, en especial de las pequeñas empresas.

Sobre la base de esos márgenes de interpretación, la CAM tiene la facultad y la obligación de defender los intereses de los agentes económicos en el mercado ante la presencia indebida ilegal y/o irrazonable, contraria a los principios de la libre competencia regulados en diversas normas vigentes en el ordenamiento jurídico peruano, de las denominadas "barreras burocráticas". Pero su actuación en este campo, para ser válida debe respetar los márgenes de su propia competencia legal, y ceñirse estrictamente a lo dispuesto en las normas de carácter imperativo que la regulan sin exceder dichos márgenes-, independientemente de que ello se pueda hacer a la invocación de defender a los particulares que se puedan ver afectados con tales "barreras burocráticas"; esto es, sin transgredir el ordenamiento legal vigente e imperativo para todos los órganos de la administración pública; y como consecuencia de ello no puede irrogarse facultades que no posee, tales como realizar el "control normativo" o el "control de legalidad o de constitucionalidad" declarando la inaplicabilidad de una norma legal o de un acto administrativo, pues esas facultades están reservadas por expreso mandato constitucional a determinados órganos constitucionales (y la CAM no es una de ellas).

Vale decir, en el caso de normas de legislación derivada de carácter particular o general están reservadas al Poder Judicial y en el caso de normas con rango de ley al Tribunal Constitucional; el primero de ellos, un poder del Estado y el segundo uno de los órganos constitucionales autónomos previstos en la Constitución, que son los únicos facultados a ejercer un control de constitucionalidad o de legalidad sobre los actos del Poder Ejecutivo, de la administración pública en general, incluyendo a la administración municipal o a la administración regional, y al Poder Legislativo.

Sexto: ¿Qué debe entenderse por competencia o facultad de la CAM para eliminar las "barreras burocráticas"?

Tenemos la plena convicción que la labor de la CAM en la facultad competencial que se le ha conferido legalmente por el Art. $26^{\circ}$ BIS de la Ley del INDECOPI (esto es, a nivel legislativo) para eliminar las "barreras burocráticas", es la de actuar conforme a lo dispuesto en su 
ley de creación o del establecimiento de sus facultades, utilizando los instrumentos procesales que confiere la Constitución y la ley con la finalidad de eliminar las "barreras burocráticas" que se originen como consecuencia de actos administrativos dictados por diversas autoridades, estableciendo las sanciones y consecuencias que correspondan.

Para ello no resulta sustentable el que pueda hacer válidamente "control de constitucionalidad" (por que no es un intérprete constitucional autorizado), ni hacer "control de legalidad" (para lo que no se halla facultado) -en verdad, además, no requiere hacerlo-. La resolución debe limitarse a detectar razonada y razonablemente la existencia una "barrera burocrática", y a partir de allí disponer en cada caso concreto la eliminación de la misma, caso por caso, disponiendo o imponiendo las multas y sanciones al funcionario o funcionarios que continúen con la "barrera burocrática", además de la responsabilidad administrativa y la denuncia penal correspondiente si tal actitud ingresa dentro de alguno de los elementos típicos del Derecho Penal Económico que hoy consagra el Código Penal en vigencia, como respaldo de la protección de la legislación de la Libre Competencia.

Lo anterior se corrobora cuando la misma normatividad que otorga la competencia legislativa a la CAM señala expresamente que: "En caso que la presunta barrera burocrática haya sido establecida en un Decreto Supremo o Resolución Ministerial (y, por extensión, en una Resolución Suprema), la CAM no podrá ordenar ni su derogación, ni su inaplicación ni imponer las sanciones antes previstas. En tales casos la resolución de la CAM se reconducirá en un informe que deberá ser elevado a la Presidencia del Consejo de Ministros para ser puesto en conocimiento del Consejo de Ministros a fin de que éste adopte las medidas que correspondan" $(S I C)$.

Consideramos con todo fundamento por ello que lo anterior también se aplica, en cuanto al "control de legalidad", de la misma manera a la normatividad legal genérica, y a los actos o hechos de la administración, provenientes de la autoridad municipal o regional. No creemos por la interpretación restrictiva que debe hacerse de toda situación o actividad excepcional, o restrictiva de derechos, conforme el principio previsto en el Art. IV del Título Preliminar del Código Civil, que dicha limitación alcance al establecimiento de las sanciones o la responsabilidad administrativa o responsabilidad para los demás funcionarios públicos (incluyendo en ello a los de la administración munici- 
pal o regional), en el ejercicio competencial de las facultades que la ley confiere a la CAM, funcionarios para quienes sí se halla aplicable lo dispuesto en el segundo parágrafo del Art. $26^{\circ}$ BIS de la Ley de INDECOPI.

Séptimo: ¿Puede la CAM disponer la derogación o la inaplicación de una norma municipal, cualesquiera sea su rango o denominación? ¿Cuál es el rango normativo de las denominadas "Ordenanzas Municipales"?

La primera parte de la presente formulación tiene los siguientes presupuestos:

(a) La facultad de control de las normas legales, cualesquiera sea su procedencia, y entendiendo el sentido material del término normas legales, está destinada a los órganos constitucionales, como ya señalamos. En el caso de las normas con rango formal de ley (con excepción de las ordenanzas municipales y las leyes regionales que no son formalmente leyes de la República, ni tienen rango de tales) al Tribunal Constitucional y, en el caso de las de legislación derivada o reglamentaria de la administración pública, (incluyendo a las municipales o regionales, con excepción de las ordenanzas municipales o las leyes regionales) al Poder Judicial.

(b) El control de la constitucionalidad de las normas en nuestro ordenamiento constitucional tiene dos vertientes, esto es: (b.1) el control concentrado de la constitucionalidad de las normas; y, (b.2) el control difuso o control judicial de la constitucionalidad de las leyes.

(c) Ambas formas de control tienen antecedentes doctrinarios e históricos muy diferentes, pues mientras en el primero caso, llamado también sistema europeo, debemos remitirnos a la obra del célebre jurista vienés Hans Kelsen, en 1919, con la implementación del Tribunal Constitucional; en el segundo de los casos nos remitimos a la Judicial Review del Derecho Constitucional norteamericano, también conocido como el control judicial de la constitucionalidad de las normas, que nace en los Estados Unidos de Norteamérica, en 1803, con la hoy célebre Sentencia del Chief of Justice (equivalente a Presidente de la Corte Suprema Federal) John Marshall en el leading case Marbury vs. Madison en un Writ Of Mandamus (el equivalente a nuestra Acción de Cumplimiento).

(d) El control concentrado de la constitucionalidad de las normas es 
aquel que realiza un órgano constitucional determinado (Tribunal Constitucional) cuya facultad primordial es la de ser el supremo intérprete de la Constitución y, a partir de esta primordial actividad, ejercitar el control las leyes expedidas por el Poder Legislativo y las normas con rango de ley determinadas por la propia Constitución (tratados internacionales, resoluciones legislativas, decretos legislativos y decretos de urgencia) ${ }^{17}$, mediante una tarea de subsunción (contrastar la interpretación de la ley dubitada con la interpretación suprema de la Constitución), a fin de que no contravengan los principios fundamentales de la carta constitucional y, en consecuencia, hacer prevalecer por sobre todas las cosas el Estado de Derecho instaurado por la Constitución del Estado. Es, pues, como ya se ha dicho, la tarea consecuente de la función que le ha asignado la Carta Constitucional de ser el auténtico intérprete de la Constitución.

Los efectos de una sentencia del Tribunal Constitucional en una Acción de Inconstitucionalidad son derogatorios erga omnes de la norma cuestionada, esto es, para todos y contra todos, donde la norma cuestionada -si la sentencia del Tribunal Constitucional es estimatoria de la demanda- dejará de tener existencia en la esfera jurídica a partir del día siguiente a su publicación, en el diario oficial El Peruano, conforme a lo previsto en el $2^{\circ}$ párrafo del Art. $36^{\circ}$ de la Ley Orgánica del Tribunal Constitucional. Ello con calidad de cosa juzgada y sin efectos retroactivos (principio ex-tunc).

(e) El control difuso de la constitucionalidad de las normas, la " $j u-$ dicial review", es la facultad constitucional de inaplicar una norma legal, atribuida en el Art. $138^{\circ}$ de la Constitución Política del Estado única y exclusivamente al Poder Judicial en un caso concreto, solo para efectos del caso mismo (Art. $14^{\circ}$ del TUO de la Ley Orgánica del Poder Judicial), y sólo en ese foro, sin que pueda válidamente tener efectos genéricos de una derogación de una norma. Como en el caso anterior, la norma inaplicada seguirá vigente para el resto del ordenamiento jurídico, y la inaplicabilidad sancionada lo será sólo para el caso donde el juzgador considere que existe una colisión entre determinada norma y el texto constitucional.

17 Aún cuando la Constitución no lo mencione, también los decretos leyes, leyes de los gobiernos de facto, por su rango normativo de ley en sentido material y formal por la fuerza de los hechos, pueden ser objeto del control del Tribunal Constitucional, y la propia Ley Orgánica del Tribunal Constitucional así lo contempla expresamente. 
Nuestro ordenamiento jurídico constitucional otorga además al Poder Judicial, como ya se señaló, la facultad de controlar la legalidad de las normas reglamentarias o de legislación derivada de carácter general, mediante la Acción Popular, y la del control de las resoluciones administrativas de carácter particular mediante la Acción Contencioso Administrativa.

Son en consecuencia cuatro los mecanismos de control de las normas y estos se utilizarán conforme a la naturaleza o carácter de la norma, cuya inconstitucionalidad o ilegalidad es materia del proceso. Se reserva al Tribunal Constitucional y al Poder Judicial la facultad de ejercer el control de las normas, son estos los únicos órganos del Estado que pueden desempeñar tal función y, como consecuencia de ello, cualesquier otro órgano de la administración pública que haga uso de esta facultad estará incurriendo en un grave problema de usurpación de funciones.

La segunda parte de la interrogante está exclusivamente referida al rango normativo de la ordenanzas municipales que son leyes municipales, esto es, expedidas por los gobiernos locales. Al respecto debemos precisar que la jerarquía normativa en el ordenamiento jurídico peruano que se grafica en el Art. $51^{\circ}$ de la Carta Constitucional, y que a la letra dice:

"Art. 51․- La Constitución prevalece sobre toda norma legal; la ley, sobre las normas de inferior jerarquía, y así sucesivamente. La publicidad es esencial para la vigencia de toda norma del Estado".

De lo que se desprende que las ordenanzas municipales no tienen ni pueden tener rango normativo de ley de la República conforme a la Constitución de 1993 (y también conforme a su antecedente de 1979 (D)), y no hay norma constitucional que contradiga lo que así estamos afirmando y nunca nadie se ha planteado esto hasta el presente periodo, en que se han escuchado de modo inédito algunas opiniones en contrario ${ }^{18}$ que pueden ser en algunos casos evidentemente interesadas o artificiosamente editadas.

18 Ernesto Blume Fortini. (Compilador) El rango de Ley de las Ordenanzas Municipales en la Constitución de 1993; AAVV; Municipalidad Metropolitana de Lima; Lima, 1997; edición ad-hoc y temática sobre esta materia. 
Lo que sucede es que en la Constitución, cuando se define la competencia del Tribunal Constitucional al definir la Acción de Inconstitucionalidad de las Leyes (con notorio defecto de redacción, dicho sea de paso), establece para las ordenanzas municipales (al igual que para las leyes regionales) un foro de control calificado, extrayéndolo del control del Poder Judicial y ubicándolo en los márgenes del control del Tribunal Constitucional. Pero es obvio que ello no "otorga" por sí mismo rango normativo de Ley a una ordenanza municipal por el sólo hecho de que su "árbitro constitucional" sea el mismo que el diseñado para el control de las leyes. Lo contrario supondría sostener que, en realidad, el rango normativo de las ordenanzas municipales se "eleva" al igual que una Ley del Congreso de la República por una suerte de mímesis constitucional ${ }^{19}$. En la realidad lo que sucede, es que cuando la Constitución define los alcances de la Acción de Inconstitucionalidad de las Leyes, se señala textualmente que:

"Art. $200^{\circ}$.- Son garantías constitucionales:

(...)

4.- La Acción de Inconstitucionalidad de las Leyes, que procede contra las normas que tienen rango de ley: leyes, decretos legislativos, decretos de urgencia, tratados, reglamentos del Congreso, (Decretos Leyes), normas regionales de carácter general y ordenanzas municipales que contravengan la Constitución la Constitución en la forma o en el fondo". (Agregado y negritas es nuestro).

Aparece evidente que las últimas dos menciones, leyes regionales y ordenanzas municipales, no constituyen en realidad normas legales con rango formal de ley, a diferencia de las demás, y el sólo hecho de mencionarlas en "conjunto" no determina per se que "adquieran" el rango normativo de Leyes de la República, ya que como queda dicho, sólo son tales las que se expidan por el Congreso Nacional, y las que ya se han mencionado en los límites del Art. $51^{\circ}$ de la Constitución.

19 Mímesis.- Imitación que se hace de una persona (o cosa), repitiendo lo que ha dicho, y remedándola en el modo de hablar y en gestos y ademanes, (...); Diccionario de la Lengua Española; Real Academia Española; XXI Ed., T.II, Madrid, 1992; p. 1374. 
Las normas que puede expedir una municipalidad o gobierno local, conforme a lo previsto en el Art. $109^{\circ}$ de la Ley de Orgánica de Municipalidades (Ley No 23853) son:
(a) Ordenanzas Municipales;
(b) Edictos;
(c) Acuerdos de Consejo;
(d) Decretos; y,
(e) Resoluciones.

Las tres primeras de las nombradas se encuentran legisladas en el Art. $110^{\circ}$ de la Ley Orgánica de Municipalidades, y son aquellas mediante las cuales los gobiernos locales ejercen sus funciones de administración y de gobierno. La norma señalada nos dice literalmente:

"Art. 110"- Las Ordenanzas son las normas generales que regulan la organización, administración o prestación de los servicios públicos locales, el cumplimiento de las funciones generales o específicas de las Municipalidades o establecen las limitaciones y modalidades a la propiedad privada.

Los Edictos son normas generales por cuya virtud se aprueban los tributos Municipales y el reglamento de Organización Interior.

Los Acuerdos son decisiones específicas sobre cualquier asunto de interés público, vecinal o institucional que expresan la opinión de la Municipalidad, su voluntad de practicar un determinado acto o de sujetarse a una conducta o norma institucional".

Los decretos de Alcaldía y las resoluciones de Alcaldía son aquellas normas de carácter estrictamente administrativo y se encuentran determinadas en el Art. $111^{\circ}$ de la mencionada norma legal, que a la letra dice:

"Art. 111\%.- Los Decretos establecen normas de ejecución de las Ordenanzas, sancionan los procedimientos necesarios a la administración Municipal o resuelven o regulan los asuntos de orden general y de interés para el vecindario.

Las Resoluciones resuelven asuntos de carácter administrativo" 
Como se aprecia de los puntos precedentes las municipalidades, como cualquier otro órgano de la administración pública, rigen su vida institucional y sus relaciones con los particulares sobre la base de una serie de normas, con denominaciones propias y que pueden ser de alcance general o particular. Cualesquiera sea la denominación que le demos a los actos administrativos que expresan la voluntad del gobierno local, estos podrán ser materia de control de la misma forma que la ley prevé para los demás casos; con la sola excepción de la Ordenanza Municipal, norma de mayor jerarquía dentro de la legislación municipal y que la Constitución le confiere en el Art. $200^{\circ}$ Inc. 4, al someterlas al control del Tribunal Constitucional y extrayéndola del natural control judicial. Lo que no supone de modo alguno que en sentido estricto estemos ante una ley, de las mismas características que las promulgadas por el Poder Legislativo.

Son normas que por mandato constitucional, y dada la importancia que tienen dentro del ámbito vecinal o comunal sobre el cual están dadas, y por su origen de legitimación popular, han sido puestas por un arbitrio de la Constitución bajo el mismo control que se le da a una ley, pero no por ello se les puede asemejar o reconocer como tal en sentido estricto, y no se puede tomar como base su carácter de general puesto que existen otras normas administrativas de alcance general que tampoco tienen el rango que la Constitución le ha reservado sólo a las leyes y a las demás ya señaladas como del mismo rango, siendo sólo una opción legislativa adoptada por nuestra Carta Constitucional que "privilegia" a las ordenanzas municipales sólo en cuanto a su control constitucional o de legalidad dentro de las diferentes normas a las que les asigna el mismo rango legal, y esto puede explicarse como consecuencia de la independencia y origen popular de los gobiernos locales, independencia y autonomía que por lo demás no supone de ninguna manera la creación de un pequeño Estado dentro del Estado Peruano (atiéndase, además, que son más de 1000 municipalidades en toda la República).

No puede un gobierno local, por más legítimo que sea (es decir, proveniente del sufragio directo de sus electores en su ámbito territorial, grande, mediano o pequeño; provincial o distrital) dictar ordenanzas, que puedan transgredir las leyes de la República, ni tampoco transgredir el ámbito territorial sobre el cual tienen competencia los municipios o gobiernos locales. 
Ahora bien, el hecho de que una ordenanza municipal no sea equivalente en sentido estricto a una Ley del Congreso, no supone que una Ley del Congreso la pueda derogar o desconocer, regulando al mismo tiempo lo que se halla reservado por la Constitución a su materia, por más rango normativo mayor que pueda tener; pues la ordenanza municipal está beneficiada por el principio de la reserva de ley que implica que dentro de los ámbitos de su competencia ninguna norma legal, por mayor rango normativo que tuviera; puede ingresar a su privativo ámbito de competencia que, por mandato de la Constitución, se halla reservada para la propia ordenanza municipal que, siendo de menor rango normativo, no puede ser superada en su contenido por una Ley de la República por el principio ya señalado, que determina que sólo una norma de igual jerarquía y dentro de la misma competencia la puede modificar por un aspecto de respeto, precisamente, competencial ${ }^{20}$.

De ningún modo se puede desconocer, y menos la CAM, que la política legislativa adoptada por nuestros constituyentes le ha conferido un rango legal a la ordenanza municipal; esto es, que para derogarse sólo se podrá hacerlo mediante otra ordenanza municipal de igual jerarquía y de la misma municipalidad, o acudir al Tribunal Constitucional, conforme a las normas en materia de Acción de Inconstitucionalidad, a fin de solicitar y lograr su derogatoria en aplicación del Sistema de Control Concentrado que nuestra carta constitucional contiene, como ya hemos señalado. Este control se ha reservado como facultad exclusiva y excluyente del Tribunal Constitucional y respecto del cual existe una legitimación cerrada, conforme a lo previsto en el Art. $203^{\circ}$ de la Constitución; y que, para el caso de las ordenanzas municipales, supone que además de las personas legitimadas para interponer la Acción de Inconstitucionalidad, esta pueda ser interpuesta por el 1\% de los ciudadanos del respectivo ámbito territorial municipal.

¿Cuál es la razón para que la Constitución tenga en el Art. 200, Inc. 4to. la previsión del "foro especial" para las ordenanzas municipa-

20 Sírvanos de ejemplo el siguiente caso: En la jerarquía judicial -también de orden piramidal- es obvio que un Juez de Primera Instancia tiene menos jerarquía que un Vocal de la Corte Suprema de Justicia de la República; pero tal Vocal Supremo no podría por más que tenga una mayor jerarquía funcional y administrativa; ingresar valida y competentemente a un caso de ese Juez de Primera Instancia y resolver como jurisdiccionales por él o darle indicaciones de cómo hacerlo. 
les? El caso de la legitimación popular en el origen de las ordenanzas municipales determinó en el espíritu del constituyente de 1993 que, pese a no ser una norma legal con rango de ley -no lo podía ser en ningún caso-, tenga el respeto a esa legitimación popular la reserva del mismo "foro de control" que es el que tiene la ley, pero ello, en ningún caso podía determinar su "automática" conversión en "norma legal municipal con rango normativo de Ley de la República (por más error en la redacción -o en la construcción del enunciado- del Inc. 4to. del Art. $200^{\circ}$ de la Constitución), ya que ordenanzas municipales no sólo expiden legalmente el Concejo Metropolitano de Lima, o de las capitales de los departamentos, o de las grandes ciudades; sino todos y cada uno de los municipios del país, que pasan de 1000. ¿Sería posible entender que, además del Congreso Nacional, hay más de 1000 "mini congresos municipales" que se hallan facultados a dictar las más variadas "normas legales" bajo el rótulo de "ordenanza Municipal", subyugando y sometiendo así el sistema jurídico nacional? No es posible hacerlo, por que la Ordenanza Municipal no tiene el mismo rango normativo de una Ley del Congreso Nacional en su contenido intrínseco; todo ello, sin perjuicio por cierto, de que la Ley del Congreso Nacional respete (no hacerlo haría inconstitucional a dicha ley), respete escrupulosamente la reserva de ley que la Constitución y la Ley de Municipalidades reserva como garantía de la autonomía de los gobiernos locales ${ }^{21}$.

Para determinar lo anterior deber recurrirse a una necesaria interpretación constitucional autorizada, bajo métodos distintos y diferentes de los que trae la hermeneútica jurídica tradicional o legal, de modo que esta interpretación constitucional autorizada -en "contrapeso de valores"-se haga "conforme a la Constitución"22.

\section{Conclusiones.-}

I. La Administración Pública está conformada por todos aquellos órganos y organismos que componen los poderes del Estado (Ejecuti-

21 Autonomía viene de la conjunción latina: auto-nomos, que significa "facultad de autonormarse o autoregularse"; es decir, de darse su propia y excluyente normatividad.

22 Aníbal Quiroga León. "La Interpretación Constitucional": Revista Derecho, No. 39 , Fac. de. Derecho, PUC del Perú, Lima, 1985; pp 323 y ss. 
vo, Legislativo y Judicial), y los órganos constitucionales autónomos, esto es los órganos cuyo origen es la carta constitucional.

II. La Administración Pública expresa la voluntad del Estado mediante el dictado de una serie de disposiciones, que se pueden denominar de diferentes maneras, dependiendo su denominación de la naturaleza de la disposición dictada: por ejemplo, las normas legales son actos administrativos de naturaleza normativa.

III. Además de las atribuciones de los diferentes órganos y organismos de la Administración Pública, estos tienen la facultad de conocer y resolver en la vía administrativa las pretensiones de los particulares frente a la Administración Pública, al evaluar e interpretar para esta labor las normas legales, la Administración Pública está ejerciendo la denominada "jurisdicción administrativa", la misma que ejerce con las mismas facultades que cuando el Poder Judicial ejerce la jurisdicción ordinaria, exceptuando la del control difuso de la constitucionalidad de las normas, conforme a lo previsto en el Art. $138^{\circ}$ de la Constitución Política del Estado y el Art. $14^{\circ}$ del TUO de la Ley Orgánica del Poder Judicial.

IV.Cuando el Art. 26 BIS de la Ley de INDECOPI se refiere a las "barreras burocráticas" que impidan u obstaculicen (ilegal o irracionalmente) el acceso o permanencia de los agentes económicos en el mercado, en especial de las pequeñas empresas, éstas podrían estar contenidas en los actos administrativos particulares o genéricos de la Administración Pública, o en los hechos de la administración, incluyendo en ello a las entidades o facultades administrativas municipales o regionales

V. Son sujetos activos de los actos administrativos, cualesquiera sea su naturaleza, los órganos y organismos de la Administración Pública que los expidan, siendo los responsables de ellos los funcionarios que los hayan expedido. Su defensa, en el caso que los actos administrativos contravengan la Constitución o las normas de mayor jerarquía, será asumida conforme a lo dispuesto en las normas correspondientes a la defensa del Estado.

VI. La facultad de control de la constitucionalidad y la legalidad de las normas legales -en el sentido lato del término-, tengan éstas efectos particulares o generales, está reservada por mandato constitucional al Tribunal Constitucional y al Poder Judicial.

VII. El Tribunal Constitucional es el órgano constitucional cuya 
función primera es la de ejercer el control de la constitucionalidad de las leyes y las normas con rango de ley. Respecto de estas últimas, es el propio texto constitucional el que se reserva la facultad de determinar cuales serán las normas legales con rango de ley, encontramos entre ellas a las ordenanzas municipales.

VIII. El Poder Judicial tiene como una de sus facultades la de ejercer el control de la constitucionalidad y legalidad de las normas legales de legislación reglamentaria o derivada y de efectos generales mediante la Acción Popular contenida en el Inc. 5 del Art. 200 de la Constitución Política del Estado; respecto a los actos administrativos de efectos particulares, el Poder Judicial es el único facultado a determinar si éstos son o no legales y/o constitucionales, mediante la resolución de las acciones contencioso administrativas, cuyo origen lo encontramos en el Art. $148^{\circ}$ de la Constitución y respecto de las cuales el único legitimado a interponerla es el sujeto que se ve afectado con el Acto Administrativo cuestionado. Cabe señalar que el Poder Judicial también tiene la facultad del control difuso o judicial de las leyes y normas con rango de ley, mediante su inaplicación a un caso concreto, conforme a lo establecido en el Art. $138^{\circ}$ de la Constitución.

IX. Las "barreras burocráticas" conforme a su definición son aquellas que obstaculizan irracionalmente el libre mercado y no se condicen con la política económica contenida en los Arts. $58^{\circ}$ y $61^{\circ}$ de la Constitución Política de Estado. Es función de la CAM la de controlar que los órganos de la Administración Pública no contravengan estas disposiciones y en consecuencia sus actos no contengan "barreras burocráticas"; más el control de la CAM no supone de modo alguno que pueda derogar o inaplicar el Acto Administrativo que la contiene, pues esta es una facultad expresamente reservada al Tribunal Constitucional y al Poder Judicial, conforme se ha señalado en el punto anterior.

$\mathrm{X}$. La obligación de la CAM de detectar la existencia de "barreras burocráticas" y eliminar su aplicación disponiendo en cada caso concreto la eliminación de la misma, caso por caso, y/o imponiendo las multas y sanciones al funcionario o funcionarios que continúen con la "barrera burocrática", además de la responsabilidad administrativa y la denuncia penal correspondiente si tal actitud ingresa dentro de alguno de los elementos típicos del Derecho Penal Económico, que hoy consagra el Código Penal en vigencia como respaldo de la protección de la legislación de la libre competencia. 
XI. Los gobiernos locales o municipalidades rigen su vida institucional y sus relaciones con los ciudadanos, mediante actos normativos que se encuentran determinados en el Art. $110^{\circ}$ de la Ley Orgánica de Municipalidades (Ley $\mathrm{N}^{\circ} 23385$ ).

XII. La norma de mayor jerarquía municipal es la ordenanza municipal, que tiene efectos generales y está determinada para regular la organización, administración o prestación de los servicios públicos locales, el cumplimiento de las funciones generales o específicas de las Municipalidades o establecer las limitaciones y modalidades a la propiedad privada.

XIII. Las ordenanzas municipales conforme a lo dispuesto en el Art. $200^{\circ}$ Inc. 4 de la Constitución, tienen rango de ley; mas ello no significa de modo alguno que una ordenanza municipal sea en sentido estricto una Ley. El rango legal que le confiere la Constitución a una Ordenanza Municipal es una opción constitucional que tiene como fundamento la naturaleza de esta norma y sus efectos dentro de un gobierno local. El hecho que en sentido estricto una Ordenanza Municipal no sea igual a una Ley del Congreso de ningún modo puede conllevar que su derogación o inaplicación la dicte el Poder Judicial o un Órgano de la Administración Pública pues ello ha sido reservado constitucionalmente expresa y exclusivamente al Tribunal Constitucional.

XIV. La previsión del "foro especial" para las ordenanzas municipales dispuesto por la Constitución se basa en la cualidad de la legitimación popular en el origen de las ordenanzas municipales que determinó en el espíritu del constituyente de 1993 a que, pese a no ser una norma legal con rango de Ley -no lo podía ser en ningún caso-, tenga un respeto a esa legitimación popular y le reserva el mismo "foro de control" que tiene la Ley. Pero ello, en ningún caso, puede determinar su "automática" conversión en "norma legal municipal con rango normativo de Ley de la República”, ya que las ordenanzas municipales no sólo se expiden legalmente por el Concejo Metropolitano de Lima, o de las capitales de los departamentos, o de las grandes ciudades, sino todos y cada uno de los municipios del país, que pasan de 1000 ¿Sería posible entender que, además del Congreso Nacional, hay más de 1000 "mini Congresos Municipales" que se hallen facultados a dictar las más variadas "normas legales" bajo el rótulo de Ordenanza Municipal, subyugando y sometiendo así el sistema jurídico nacional? No es posible 
hacerlo, porque la ordenanza municipal no tiene el mismo rango normativo de una Ley del Congreso Nacional en su contenido intrínseco; sin perjuicio por cierto, como en puridad corresponde, de que la Ley del Congreso Nacional respete y no se inmiscuya en lo que es su "reserva de ley", esto es, en su materia, en su contenido normativo, y en su orden competencial, respetando escrupulosamente esta "reserva de ley" que la Constitución y la Ley de Municipalidades reserva como garantía de la autonomía e independencia de los gobiernos locales. Nada menos que eso, y no más que eso. Ese es el adecuado equilibrio que la Constitución ha determinado para la convivencia de la ordenanza municipal y de la Ley de la República emanada del Congreso Nacional. 